\title{
IMPAIRED MASTICATORY FUNCTION AND TEMPOROMANDIBULAR DYSFUNCTIONS IN CHILDREN
}

\author{
Amr E. Abdel Latif*
}

\begin{abstract}
Aim: This study has been conducted for the purpose of investigating the prevalence of TMDs clinical signs and their association with impaired masticatory function, because of dental caries and loss of primary and/or permanent molars in children.

Subjects and Methods: The study has implicated (234) children, their ages have ranged from six to nine years, they have been randomly selected, divided into two groups based on their dental status. Group I: $(n=115)$ has included unilateral or bilateral advanced dental caries of primary and/or permanent molars. Whereas the group II: $(n=119)$ has consisted of unilateral or bilateral premature loss of primary teeth and/or loss of permanent molars because of dental caries. The patients have been assessed in order that the clinical signs of TMDs could be evaluated through a physical examination .
\end{abstract}

The results: Among all subjects, 77 (32.9\%) have been identified as TMD patients, comprising of $36(31.3 \%)$ patients of the group I, $41(34.5 \%)$ patients of the group II. At the present study, the relationship between the clinical signs of TMD in both groups has been statistically insignificant, except for a maximum mouth opening.

Conclusion: Relying on the findings of study on Egyptian dental patients, at ages of 6-9 years old, it has been concluded that more than $30 \%$ of the patients whom they have experienced dental caries or premature loss of primary molar and/or loss of permanent molars have clinical signs of TMD.

\section{INTRODUCTION}

Temporomandibular joint (TMJ) has considerable consequences at the clinical characteristic of the stomatognathic system. Temporomandibular dysfunctions (TMD) has been a term of preference for a group of signs as well as the symptoms influencing the TMJ and masticatory muscle ${ }^{(1)}$.
In accordance with the American Dental Association (ADA), specific signs and manifestations have essentially characterized temporomandibular disorders; implicating pain in the Temporomandibular joint, deviation or restriction of mandibular movements, chewing muscular tissues, unordinary noise at a certain stage while moving the jaw, as well as the headache and the neck ache. ${ }^{(2)}$.

\footnotetext{
* Associate Professor of Pediatric Dentistry and Dental Public Health, Faculty of Dentistry, Cairo University.
} 
A high indecision of signs and manifestations of such disorders in children, similar to those seen in adults, have been reported by many studies. About $60-70 \%$ of the population is indicated by studies as having at least one sign of TMD, at some stage of their life ${ }^{(3-5)}$. Prevailing signs and symptoms of TMD in a population-based report have varied considerably among children and teen-agers, such a variation has ranged between $6 \%$ and $68 \%{ }^{(6)}$. Most studies have disclosed that the TMDs have occurred in children and teenagers as well as tending to progress at the start of an adult life ${ }^{(1)}$

Abnormal occlusion and alteration of masticatory apparatus powerfully affect stomatoganthic system. In case there are parafunctional activities (non-functional) due to caries or molars loss, the loss of posterior dental support will rise the load on the TMJ, resulting in its deformity ${ }^{(7)}$.

This study has been implemented for the purpose of investigating the prevalence of TMDs clinical signs and their association with impaired masticatory function, because of dental caries and/ or loss of primary and permanent molars in children receiving treatment at the Pediatric Dentistry and Dental Public Health Department, at the Faculty of Dentistry, Cairo University.

\section{SUBJECTS AND METHODS}

\section{Study design and setting}

A sample including (234) children has been selected randomly from the outpatient clinic at the Pediatric Dentistry and Dental Public Health Department, Faculty of Dentistry, Cairo University, and has been included within this correlational study.

\section{Subjects}

A written consent has been received by the child's parents /caregivers, which was previously approved by the ethics committee in order that they could be filled before an examination. Participating in the study has been voluntary, and the children have been included on the basis of the following inclusion criteria: medically free patients ,ages ranging from six to nine years (including both genders), the patients must not have any bad oral habits, such as finger/thumb sucking or nail/check biting, or bruxism.

\section{Sample size}

The study sample has been counted statistically following Raosoft computer software (Raosoft, Inc) ${ }^{(8)}$. For purpose of being able to reject the null hypothesis, studying at least 215 subjects was recommended by the estimation.

\section{Methods}

For purpose of specifying the selected patients/ day. Research randomized software (http//www. randomizer.org/) (9) freely available online was adopted ${ }^{(9)}$. the number/codes of the 5 patients/day was randomly chosen by the software in order to be included in the study till obtaining the total sample size. Based on their dental status, the patients have been divided into two groups. Group I $(n=115)$ have been patients with unilateral or bilateral carious primary and/or permanent molars, the caries have included advanced caries in accordance with ADA caries classification for purpose of a clinical practice ${ }^{(10)}$. Group II has been the patients with unilateral or bilateral premature loss of primary molars, and/or loss of permanent molars because of dental caries $(n=119)$.

In order to evaluate the clinical signs of TMDs, the patients have been assessed through a physical examination. These have been comprised of :

1. Tenderness of Temporomandibular joint and soft tissues, particularly the muscles concerning the joint complex. The examination has been conducted by gentle palpation following the index fingers in the depression made behind each condyle, just at the front side of the tragus of the ear, 
on both sides of temporomandibular joint during the movement of jaw in order to verify pain or tenderness on various parts of TMJ. Muscle examination has been implemented bilaterally through light palpation of the supplemental oral masticatory muscle (masseter and temporalis muscles) while in light clenching and relaxation. The subject has been asked whether the palpation is painful or just uncomfortable and the response has been recorded ${ }^{(11)}$.

2. Deviation of mandibular movement during mouth opening, the opening deviation has been specified as the shifting of the mandible, at least $2 \mathrm{~mm}$. to the right or the left side during mouth opening ${ }^{(12)}$. A penciled mark has been created on the surface of maxillary incisor, conformable with the mandibular midline, followed later by making the measurement .

3. Mouth opening at maximum with/without pain, the child has been requested to open his/her mouth the possible maximum extent. The vertical distance among the incisal edges of the mandibular and opposing maxillary central incisors has been measured by the use of millimeter ruler .The amount of vertical incisor overbite has been added to the measurement so that the actual amount of mouth opening could be calculated. Based on World Health Organization (WHO.1987), maximum mouth opening of less than $30 \mathrm{~mm}$. has been regarded as a restricted mouth opening ${ }^{(13)}$.

4- Auscultation of joint sounds has been aimed to detect strange noises, the subject has been requested to open as wide as he/she could, even if it has caused pain, then asked to close. The teeth ought to be brought by each closure completely together in maximum intercuspation. TMJ sounds have been examined through stethoscope, or without, by listening to joint sounds through examiner's ear within $5 \mathrm{~cm}$. of the TMJ ${ }^{(14)}$.
All the findings have been expressed as being present or absent. The statistical software adopted has been the Statistical Packages for the Social Science (SPSS), version 23.0 (IBM, Armonk, NY). Data has been described statistically in terms of frequency and percentage of distribution. Comparison between different groups concerning categorical variables has been examined following Chi-square test, the level of significance has been $5 \%$ in all conducted tests.

\section{RESULTS}

At the present study, 234 children have been divided into two groups, based on their dental status. Group I $(n=115)$ has been composed of children between 6-9 years of age (mean age 8.1 years) having unilateral or bilateral advanced dental caries of primary and/or permanent molars. Group II $(n=119)$ has been at same age category (mean age 8.7 years) having unilateral or bilateral premature loss of primary teeth and/or loss of permanent molars because of dental caries.

It has been revealed by clinical dental diagnosis prior to TMD clinical signs examination that: among 115 patients of group I, 73 patients have bilateral advanced caries affecting the posterior teeth, 42 patients have unilateral teeth affection. Whereas in group II, bilateral molars extraction has been presented in 32 patients, 87 patients have shown unilateral teeth extraction, regardless the arch affected. Among all subject, 77 (32.9\%) specified as TMD patients , implicating 36 (31.3\%) patients of group I, $41(34.5 \%)$ patients of group II. The finding has been statistically analyzed (Chi-square test) in order that the influence of affected teeth distribution (unilateral vs. bilateral) on the clinical signs of TMD could be evaluated. Regarding affected teeth distribution, the distribution in group II has been significant at P-value $=0.02$. Whereas there has not been any statistically significant difference concerning carious teeth 
distribution of group I (table $1 \&$ figure 1).

Table (2) has shown descriptive statistic ( number and frequency) concerning type of affected teeth in both groups. First primary molar has been the most common tooth affected as carious or untimely extracted followed by secondary primary molar and first permanent molar.

The distribution of clinical signs of TMD in both groups have been shown in table 3 \& figur 2. It has been shown through findings of study that, out of 115 of children of group I, TMJ and/ or muscular tenderness have been experienced by 9 patients $(7.8 \%)$, whereas $16(13.4 \%)$ of group II have experienced similar diagnostic criteria. The outcomes have shown that 30 (12.4\%) of all subjects have had a mandibular deviation on maximum opening; $11.3 \%$ of the children of group I and $14.3 \%$ of group II. Prevalening mandibular opening restriction has been 7 per cent and 8.1 per cent, for both groups, consecutively. Mouth opening of less than $30 \mathrm{~mm}$ has been regarded as restricted in the current study. With clicking symptoms, tempomandibular joint dysfunction can be experienced during the following cases: opening the mouth, closing the mouth, or opening and closing the mouth, joint noises have been detected in 29.4 percent of all patients, 13.9 percent of the patients with dental caries and 16 percent of patient with extractions. Collective data has demonstrated that 28 patients have shown more than one of the signs of TMD. Statistical analysis have been adopted so as to test the relation among the clinical signs of TMD in both groups that has been statistically insignificant with an exception for maximum mouth opening $(\mathrm{P}=.000)$.

\section{DISCUSSION}

Despite the fact that many studies have been

TABLE (1) Number and percentage of children regarding the distribution of affected teeth

\begin{tabular}{|c|c|c|c|c|c|c|c|c|}
\hline \multirow[b]{2}{*}{$\begin{array}{c}\text { Teeth } \\
\text { distribution }\end{array}$} & & \multicolumn{3}{|c|}{ Group I } & \multicolumn{4}{|c|}{ Group II } \\
\hline & & $\begin{array}{c}\text { Patients With } \\
\text { TMD signs }\end{array}$ & $\begin{array}{l}\text { Patients Without } \\
\text { TMD signs }\end{array}$ & Total & $\begin{array}{c}\text { Patients With } \\
\text { TMD signs }\end{array}$ & $\begin{array}{l}\text { Patients Without } \\
\text { TMD signs }\end{array}$ & Total & P-value \\
\hline Unilateral & $\begin{array}{l}\mathrm{n} \\
\%\end{array}$ & $\begin{array}{c}15 \\
13 \%\end{array}$ & $\begin{array}{c}27 \\
23.5 \%\end{array}$ & $\begin{array}{c}42 \\
36.5 \%\end{array}$ & $\begin{array}{c}14 \\
11.8 \%\end{array}$ & $\begin{array}{c}73 \\
61.3 \%\end{array}$ & $\begin{array}{c}87 \\
73.1 \%\end{array}$ & 0.528 \\
\hline Bilateral & $\begin{array}{l}\mathrm{n} \\
\%\end{array}$ & $\begin{array}{c}21 \\
18.3 \%\end{array}$ & $\begin{array}{c}52 \\
45.2 \%\end{array}$ & $\begin{array}{c}73 \\
63.5 \%\end{array}$ & $\begin{array}{c}27 \\
22.7 \%\end{array}$ & $\begin{array}{c}5 \\
4.2 \%\end{array}$ & $\begin{array}{c}32 \\
26.9 \%\end{array}$ & $0.026^{*}$ \\
\hline Total & $\begin{array}{l}\mathrm{n} \\
\%\end{array}$ & $\begin{array}{c}36 \\
31.3 \%\end{array}$ & $\begin{array}{c}79 \\
68.7 \%\end{array}$ & $\begin{array}{c}115 \\
100 \%\end{array}$ & $\begin{array}{c}41 \\
34.5 \%\end{array}$ & $\begin{array}{c}78 \\
65.5 \%\end{array}$ & $\begin{array}{c}119 \\
100 \%\end{array}$ & \\
\hline
\end{tabular}

*Statistical significance difference $P<0.05$

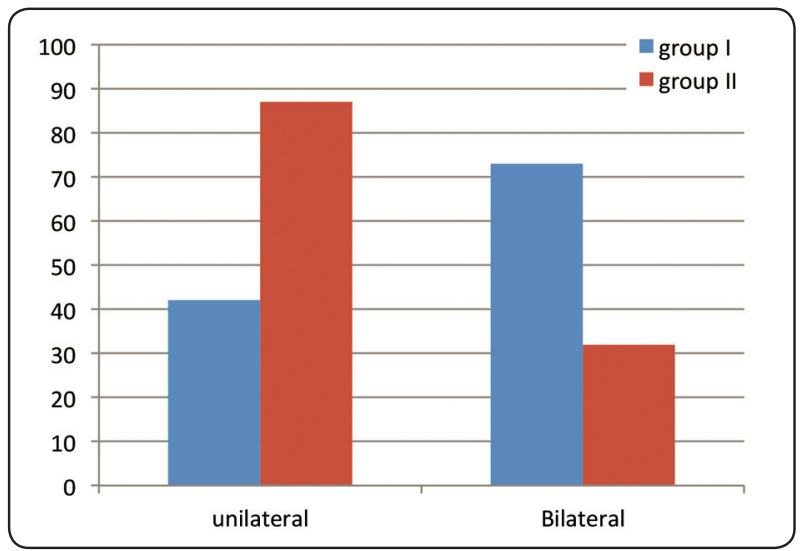

Fig. (1) Bar graph represent distribution of affected teeth. 
TABLE (2) Number and percentage of teeth regarding the type of affected teeth

\begin{tabular}{|c|c|c|c|c|c|c|c|}
\hline \multirow{2}{*}{\multicolumn{2}{|c|}{ Affected teeth }} & \multicolumn{3}{c|}{ Group I } & \multicolumn{3}{c|}{ Group II } \\
\cline { 3 - 8 } & & Mandibular & Maxillary & Total & Mandibular & Maxillary & Total \\
\hline \multirow{2}{*}{ First primary molar } & $\mathrm{n}$ & 155 & 49 & 204 & 148 & 25 & 173 \\
& $\%$ & $76 \%$ & $24 \%$ & $100 \%$ & $85.5 \%$ & $14.5 \%$ & $100 \%$ \\
\hline Second primary molar & $\mathrm{n}$ & 144 & 30 & 174 & 97 & 15 & 112 \\
& $\%$ & $82.8 \%$ & $17.2 \%$ & $100 \%$ & 86.6 & 13.4 & $100 \%$ \\
\hline First permanent molar & $\mathrm{n}$ & 14 & 6 & 20 & 11 & 4 & 15 \\
& $\%$ & $70 \%$ & $30 \%$ & $100 \%$ & $73.3 \%$ & $26.7 \%$ & $100 \%$ \\
\hline
\end{tabular}

TABLE (3) Number and percentage of subjects with tenderness, deviation and limitation of mouth opening and TMD noise .

\begin{tabular}{|c|c|c|c|c|c|}
\hline \multicolumn{2}{|l|}{ Clinical signs } & Group I & Group II & Total & P value \\
\hline Tenderness & $\mathrm{n}$ & 9 & 16 & 25 & .800 \\
& $\%$ & $7.8 \%$ & $13.4 \%$ & $10.7 \%$ & .561 \\
\hline Opening deviation & $\mathrm{n}$ & 13 & 17 & $12.8 \%$ & $.000 *$ \\
\hline Maximum opening & $\mathrm{n}$ & $11.3 \%$ & $14.3 \%$ & 19 & $.1 \%$ \\
\hline TMJ noise & $\mathrm{n}$ & 8 & $9.2 \%$ & 35 & .325 \\
& $\%$ & 16 & 19 & $15 \%$ & \\
\hline
\end{tabular}

*Statistical significance difference $P<0.05$

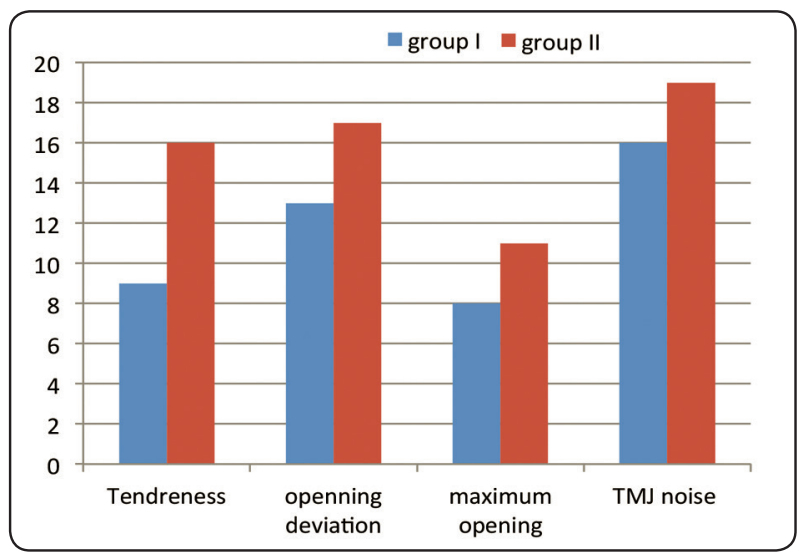

Fig. (2) Bar graph represent distribution of clinical signs of TMD. implemented for evaluating the prevalence of TMD in mixed dentition, the outcomes of these studies have often been inclusive and contradictory. Furthermore; up to our Knowledge, the TMDs has never been assessed by previous with regards to impaired masticatory function. The major objective goal of this study has been to investigate the connection among impaired masticatory function due to dental caries or teeth loss and prevalening of clinical signs of TMD. The study has been implemented on a sample of 234 children (of both genders) ranging from 6 - 9 years of age (mean age $=8.4$ ). The subjects have been divided into two groups based on their dental status. The difference in the mean ages among the groups has 
not been statistically significance $(\mathrm{P}>.05)$. This fact is significant while judging TMD prevalence due to the fact that some authors have reported a higher prevalence in older subjects. Generally, the least age for valid response is 7 years ${ }^{(15)}$. Any how, at the present study, all patients of less than 7 years of age have been sufficiently co-operative .

Patients with parafunction habits (nail/check biting, bruxism or finger and thumb sucking) are eliminated by the inclusion criteria in the present study which has been considered as a risk to develop TMD signs and symptoms .The subjects selected for group II have been patients with advanced dental caries in order that the impairment of the masticatory function could be confirmed

The skeletal component, the muscle of mastication, the neural component, and the teeth are comprised of the masticatory system. The TMJ has functioned as the fulcrum for rotation of the mandible in various directions. Any functional disturbance takes place to the TMJ will have an influence on the muscle of mastication and vice versa, any disturbance occurring to the muscle of mastication will have an influence on the TMJ. Bad eat habit such as one-sided mastication may be caused by impaired occlusion. The most frequent TMDs are due to the one-sided mastication habit ${ }^{(16)}$. Discomfort in chewing on one side of the jaw, due to dental caries or teeth loss, may be led to occlusal contact disorder resulting in chewing function shifting initially began consciously, and will ultimately become an unconscious habit ${ }^{(17)}$.

Temporomnadibular dysfunction may take place to the patient with unilateral and bilateral teeth affection. The temporomandibular joint dysfunction with clinical signs mostly happen with bilateral teeth affection have been shown by the results (table1).

At the current study, the prevalence of children specified as TMD patients, has been $32.9 \%$ of all patients. The studies obtained in Keeling et al. (1994) have been lower than this data ${ }^{(18)}$, they have found out a prevalence of $10 \%$ and $(16.53 \%)$ in children aged 6-12 years, while Alamoudi et al. (1998) reported prevalence of $16.53 \%$ in children aged 3-7 years ${ }^{(19)}$. However, the age of the sample analyzed in this study has been different. Such variation may be resulted from the various assessment methods, as well as from the dental status of all subjects who have been selected in the present study, as impaired masticatory function (due to caries or teeth loss) may be regarded as a risk factor for TMDs. Through this current work, the selected patients have been at ages 6-9 years so as to confirm that, loss of teeth at this age has been treated as an untimely loss prior to the shedding time.

Clinical signs of dysfunction, as tenderness to palpation in muscles, and TMJs have been criteria that might be influenced by intraobserver differences, mostly as a result of the amount of pressure applied to the tissue. Subsequently, within this study, all subjects have been examined by the same investigator. The fact that all subjects were examined by only one observer so that the reliability of the recordings could be strengthened.In the current work, TMJ or masticatory muscles tenderness has been detected in $10.7 \%$ among all subjects. This prevalence has been low when compared with Da Rocha et al ${ }^{(1)}$. Furthermore; the findings of this investigations have been higher than that reached by Tuerling and Limme ${ }^{(15)}$. These differences could have been due to the various palpation mechanism, individual reaction of palpation and dental status of patients.

Thirty subjects (12.4\%) have been shown by the results of having a mandibular deviation on maximum opening. The results of this study have been lower than that obtained by to Da Rocha et al. (2015), who found that 32 per cent of 3-15 years subjects had been diagnosed as TMD patients at status of deviated mouth opening ${ }^{[1]}$. This deviation can be regarded as adaptation of the mandible in the existence of interferences which lead to asymmetric muscular activity. The children have been trained 
before being examined, subsequently, they conducted frank movement during mouth opening.

Impaired range of mandibular movement was found in $8.1 \%$ of the subjects . Based on World Health Organization (WHO. 1987), children with maximum mouth opening of less than $30 \mathrm{~mm}$. have been regarded as restricted mouth opening ${ }^{(21)}$. This result was not confirmed with the result obtained by Alamoudi et al. (1998) who observed that $1.7 \%$ of the sample, 502 subjects aged 3-7 years , presented restricted mouth opening ${ }^{(15)}$. Bonjardiam (2004) analyzed children aged 3-5 years, the results revealed that $4.04 \%$ of the subjects presented restricted ranges of motion ${ }^{(2)}$. These difference could be related to variable age of the subjects under investigation, range of motion defined as restricted mouth opening and dental status of the study samples.

In the present study TMJ sound was found in $15 \%$ of the subjects. Laksitowati et al. (2009) found that $36 \%$ of students aged 6-12 years old who experience primary molar premature loss have temporomandibular joint dysfunction with clicking symptoms ${ }^{[7]}$. Clinical procedures, age of the patients and criteria for recording joint sounds have been found different in the various reports, and this, concerted with natural variations, is supposedly the cause for wide range of joint sounds appearance.

More patients in group II have shown TMDs than those of the group I. This could be demonstrated by the fact that, the masticatory functions are mightily influenced by tooth loss, more than the existence of carious teeth that may aid in mastication with some limitations unless there has been a severe pain. Table(1) has shown that there were no statistical difference between both groups concerning the clinical signs of TMD, with an exception of restriction of mouth opening $(\mathrm{p}=000)$

\section{CONCLUSION}

Teeth are part of the oral cavity, they have a significant function. Dental caries, teeth loss and subsequent impairment of the Masticatory function may occur if teeth are not preserved. Masticatory disturbance may be regarded as a starting stage of the temporomandibular joint dysfunction. Based on Egyptian dental patients' study results for ages of 6-9 years, it has been concluded that more than $30 \%$ of patients experiencing dental caries or premature of primary molar loss and/or loss of permanent molars have clinical signs of TMD

\section{REFERENCES}

1. DaRochaJG,CaralhoLS, Chetelat ES. Temporomandibular disorder in children at deciduous and mixed dentition. Braz Dent Sci. 2015;18(4):89-96.

2. Bonjardim LR, Gavião MB, Pereria L J , Castelo PM.Mandibular movement in children with and without signs and symptoms of temporomandibular disorders. J. Appl. Oral Sci. 2004; 12(1):39-44.

3. Kritsineli M, Shim YS. Malocclusion, body posture, and temporomandibular disorders in children with primary and mixed dentition. J Clin Pediatr Dent. 1992; 16:86-93.

4. Manusson T, Egermark-Eriksson I, Carlsson G. Four-year lontiduntoual study of mandibular dysfunction in children. Community Dent Oral Epidemiol. 1985;13:117-20.

5. Feteih RM. Sign and symptoms of temporomandibular disorders and oral parafuctions in urban Saudi Arabian adolescents: a research report. Head Face Med. 2006;2:25.

6. Okeson J. $6^{\text {th }}$ ed. St Louis Mosby Elsevier; 2008. Management of Temporomandibular Disorders and Occlusion ; p.631.

7. Laksitowati RH. Frequency of temporomandibular joint dysfunction with clicking symptoms due to primary molar premature loss in children aged 6-12 years old. Padjadjaran Journal of Dentistry. 2009;21(1):51-56.

8. Raosoft, Inc. www.raosoft.com/samplesize

9. http//www.randomizer.org/ 
10. YoungDA, G. G. Zeller GG, Hart R, T. C. Hart TC, Truelove EL. The American Dental Association Caries Classification System for Clinical Practice. A report of the American Dental Association Council on Scientific Affairs.JADA. 2015;146(2):79-86.

11. Dworkin S, Huggins KH, LeReche I, Von Korff M. Epidemiology of signs and symptoms in temporomandibular disorders. Clinical signs in cases and control. JADA. 1990;120: 273-281.

12. Gross A, Gale EN. A prevalence study of the clinical signs associated with mandibular dysfunction. J Am Dent Assoc. 1983; 107: 932-936.

13. Sonmez H, Sari S, Okask Oray G, Houston JB, Camdevrin H. Prevalence of temporomandibular dysfunction in Turkish children with mixed and permanent dentition. Journal of Oral Rehabilitation. 2001;28(3):280:285.
14. Goho C, Jones HL. Association between primary dentition wear and clinical temporomandibular dysfunction signs. Pediatr Dent. 1991; 13: 263-266

15. Tuerling V,LimmeM. The prevalence of temppomandibular joint dysfunction in the mixed dentition . European journal of orthodontics. 2004;26(3):311-320.

16. Ogura T. Epidemiological research about TMJ dysfunction syndrome at teenager. The J of Clin Ped Dentist. 1990;16;1

17. Ramfjord SP, Ash MM. Occlusion. $3^{\text {rd }}$ ed. Phi;ladelphia;: W. Saunders Coi; 1983. P. 145-7.

18. Keeling S, Mc Gorray S, Wheeler T, King G.Risk factors associated with temporomandibular joint sounds in children 6-12 years of age. Am J Orthod Dentofac Orthop. 1994;105:279-287.

19. Alamoudi N, Farasi N, Salako NO, Feleih R. Temporomandibular disorders among school children . J Clin Pediatr Dent. 1998;22(4):323-8. 